\title{
Effect of hypothalamic lesions on temperature regulation in hibernating ground squirrels*
}

\author{
D. J. WEIDLER, A. M. EARLE, G. G. MYERS AND G. C. SIECK \\ Department of Physiology and Biophysics and Department of Anatomy, College of Medicine, University \\ of Nebraska, Omaha, Nebr. and the Upjohn Center for Clinical Pharmacology, The University of \\ Michigan Medical Center, Ann Arbor, Mich. 48104 (U.S.A.)
}

(Accepted September 19th, 1973)

The evidence for the importance of the hypothalamus in hibernation in mammals was reviewed recently by Mrosovsky ${ }^{3}$. The role played by anterior hypothalamic and preoptic areas in the regulation of body temperature in non-hibernators is well known; a few studies seem to indicate that these areas are important in hibernators as well. Satinoff ${ }^{4,5}$ found that ground squirrels, made hypothermic by hypercapnic hypoxia, required 2-6 times longer than controls to reach normal body temperatures when they were subjected previously to preoptic-anterior hypothalamic lesions. Ground squirrels lesioned in the preoptic-anterior hypothalamic area or ventromedial hypothalamic nucleus entered hibernation, but died after 11 to 12 days, whereas normal controls aroused $^{6}$. Williams and Heath ${ }^{7}$ reported that heating the preoptic hypothalamic region of ground squirrels decreases metabolic rate and body temperature, while cooling of this region yields the opposite effects. The aim of the present study was to assess the effect of hypothalamic lesions on temperature regulation in hibernating ground squirrels.

Eight thirteen-lined ground squirrels, Citellus tridecemlineatus, were used in this study. Under pentobarbital anesthesia, a calibrated thermistor was placed surgically in the left peritoneal cavity next to the diaphragm. Wires from this thermistor led subcutaneously to an electrical coupling which was sutured to the dorsal aspect of the neck. In animals receiving lesions, stereotaxically placed, stainless steel electrodes were used to produce bilateral lesions in the hypothalamus; currents of 3-5 mA for periods of $5 \mathrm{sec}$ were used. Animals were permitted to recover from surgery at room temperature for approximately 5 days prior to subsequent hibernation studies. Hibernation was induced by placing the squirrels into a hibernation chamber; the chamber temperature was maintained at $5 \pm 0.25^{\circ} \mathrm{C}$ by a thermostat. The time required to induce hibernation initially varied from several hours to several days, and throughout the induction period, body temperature was monitored as a function of

\footnotetext{
* Reprint requests should be sent to D. J. Weidler, Upjohn Center for Clinical Pharmacology, The University of Michigan Medical Center, Ann Arbor, Mich. 48104, U.S.A.
} 


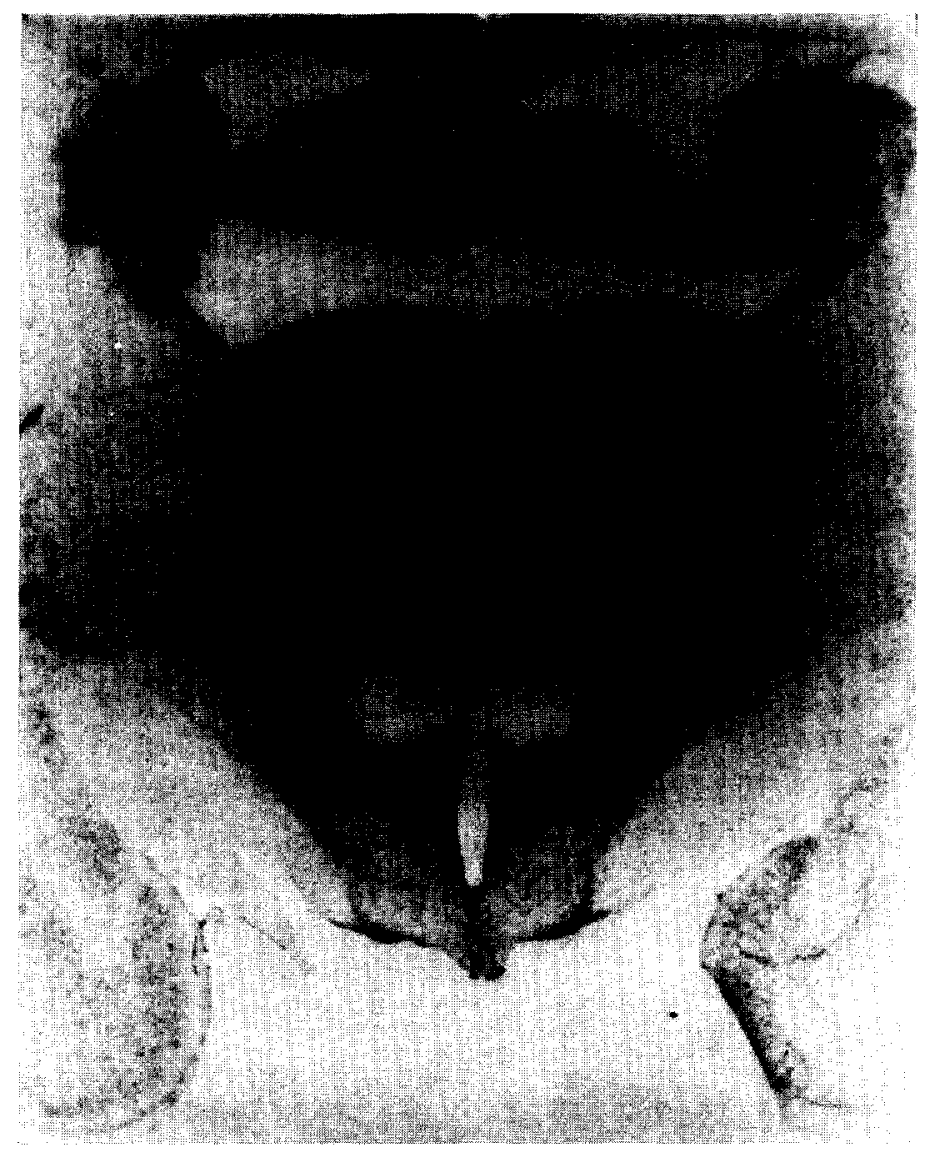

Fig. 1. Bilateral anterior hypothalamic lesions in animal T37. The relationship of body temperature and time during the entrance into hibernation for this animal and 3 other lesioned ground squirrels is compared with that found in control animals in Fig. 2.

time. After induction into hibernation (i.e., after the body temperature was within $0.5-1.0{ }^{\circ} \mathrm{C}$ of the chamber temperature), squirrels were kept in the hibernation chamber for at least $24 \mathrm{~h}$ with continuous monitoring of body temperature. The body temperature was recorded on a Clevite Corporation Mark 260 oscillograph, the signal passing first through a Brush Universal coupler-preamplifier (Model 114307-00).

To terminate experiments, squirrels were returned to normal room temperature, which precipitated their arousal; subsequently they were killed by intracardiac perfusion with normal saline followed by formol-saline. Brains were removed and fixed in $10 \%$ formalin prior to sectioning on a freezing microtome. Alternate sections were stained and examined to determine the extent of the bilateral lesions.

In the present work, lesions were placed in two general hypothalamic regions, anterior and posterior. Four squirrels (T32, T37, T38, T42) had bilateral lesions in the anterior regions (Fig. 1); the relationship between body temperature and time 


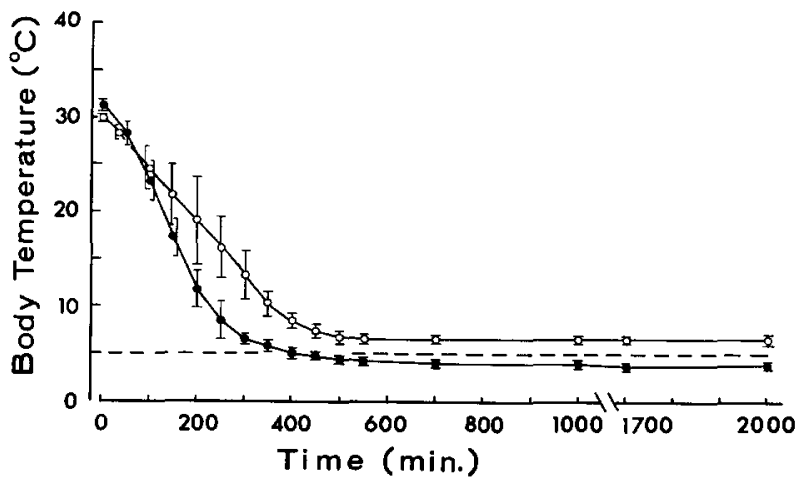

Fig. 2. The relationship between body temperature and time during entrance into hibernation for 4 ground squirrels, which had bilateral anterior hypothalamic lesions (closed circles), and 3 control animals, which had only sham surgery (open circles). There is a persistent significant difference at the 0.05 level after $300 \mathrm{~min}$. The vertical lines represent the extent of twice the standard error of the means. The horizontal dashed line represents the environmental (chamber) temperature.

during entrance into hibernation for these 4 lesioned ground squirrels was compared with that found in 3 sham-operated control animals (Fig. 2). A common starting point was obtained by producing hibernation in each animal and then precipitating arousal by exposing it to normal room temperature. When the body temperature reached $30^{\circ} \mathrm{C}$, the experiment was begun by placing the animal in the hibernation chamber; this point in time corresponds to time zero in Fig. 2 . The body temperature of T37 dropped to $5^{\circ} \mathrm{C}$ in $350 \mathrm{~min}$, while the body temperatures of T32, T38 and T42 required $350-450 \mathrm{~min}$ to decline to $5^{\circ} \mathrm{C}$. Subsequently, body temperatures slowly dropped below the chamber temperature; at the termination of experiments (after $2000 \mathrm{~min}$ ), the body temperatures of animals $\mathrm{T} 37$ and T38 were $3.4{ }^{\circ} \mathrm{C}$ while those of animals $\mathrm{T} 32$ and $\mathrm{T} 42$ were $3.9^{\circ} \mathrm{C}$ and $3.8^{\circ} \mathrm{C}$ respectively. Using the $t$-test at the 0.05 level of significance, we demonstrated a persistent significant difference between the lesioned group and the control group after $300 \mathrm{~min}$.

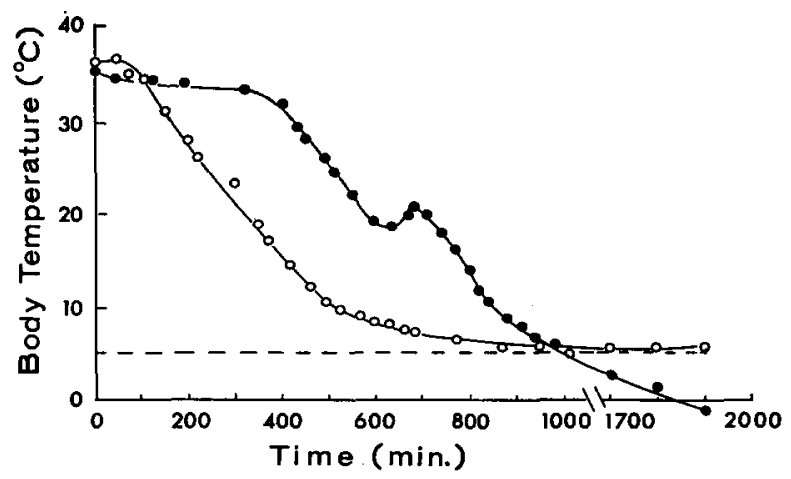

Fig. 3. The relationship between body temperature and time during entrance into hibernation in animal T4. Open circles represent data obtained prior to the placement of bilateral posterior hypothalamic lesions, and closed circles represent data from the post-lesioned state. The horizontal dashed line represents the environmental (chamber) temperature. 
One ground squirrel (T4) was lesioned bilaterally in the posterior hypothalamic area; prior to lesioning, a hibernation cycle was monitored as a control. The relationship of body temperature and time during entrance into hibernation in both pre- and post-lesioned states is presented in Fig. 3. After lesioning, the body temperature reached $5{ }^{\circ} \mathrm{C}$ in $1000 \mathrm{~min}$, and subsequently fell below the ambient temperature. This decline in body temperature continued to a level of $-0.5^{\circ} \mathrm{C}$, remained at this level for about $1 \mathrm{~h}$, and then spontaneous arousal occurred. Following this experiment, the calibration of the thermistor was verified.

From the above observations, several generalizations emerge. First, bilateral hypothalamic lesions in both the anterior and posterior hypothalamic regions profoundly affect body temperature regulation during hibernation. Second, the instantaneous rate of fall of body temperature in ground squirrels with anterior hypothalamic lesions is faster than in normal controls during the entrance into hibernation (Fig. 2). Third, the presence of both anterior and posterior hypothalamic lesions result in body temperatures dropping significantly below the environmental temperature during hibernation; this phenomenon is never observed in normal ground squirrels.

Hammel $^{2}$ proposes that two sets of sensory neurons, hi-Q $\mathrm{Q}_{10}$ and lo- $\mathrm{Q}_{10}$, located in the rostral hypothalamus, are influenced by temperature and synapse with primary motor neurons involved with thermoregulation. Hi- $\mathrm{Q}_{10}$ neurons appear to be active at body temperatures above $30^{\circ} \mathrm{C}$; when activated by an increase in body temperature, they facilitate heat loss and inhibit heat conservation mechanisms. Lo-Q10 neurons have the opposite effects and are active at lower body temperatures. These two groups of neurons may be related reciprocally, effecting the set-point of the hypothalamic temperature control mechanism; our lesions may disrupt such a relationship and consequently alter the set-point.

Hypothalamic descending fibers were reported to proceed caudally in a ventral paramedial course in the rat ${ }^{1,8}$; a similar pattern of fiber distribution was observed in ground squirrels using techniques of silver impregnation of degenerating axons (Earle, A.M., D. J. Weidler and G. G. Myers, in preparation). Because of this relationship, posterior hypothalamic lesions could destroy thermoregulatory efferent fibers, and result in the impairment of temperature regulation during hibernation as in animal T4 (Fig. 3).

The significance of the present work is that it demonstrates the importance of the hypothalamus in temperature regulation during hibernation. Mrosovsky ${ }^{3}$ states that the body temperature of normal hibernating mammals is maintained above the environmental temperature, sometimes several degrees higher; this contention was verified in the present study. However, both anterior and posterior hypothalamic lesions in hibernating ground squirrels resulted in body temperatures which were significantly lower than the environmental temperature. We conclude that anterior and posterior hypothalamic lesions interfere with a hypothalamic thermoregulatory system which is essential to temperature regulation during hibernation. One mechanism by which the body temperature may be decreased below the ambient temperature is evaporative cooling through respiration. The control center of such cooling mechanisms probably is located in the hypothalamus. 
This work was supported by U.S. Public Health Service Institutional Research Support Grants FR 5391 to the University of Nebraska College of Medicine and 5 P11 GM15559 to the Upjohn Center for Clinical Pharmacology, The University of Michigan Medical Center.

1 Guillery, R. W., Degeneration in the hypothalamic connexions of the albino rat, J. Anat. (Lond.), 91 (1957) 91-115.

2 Hammel, H. T., Temperature regulation and hibernation. In K. C. Fisher, A. R. Dawe, C. P. Lyman, E. Shonbaum, and F. E. Smith (Eds.), Mammalian Hibernation III, Oliver and Boyd, Edinburgh, 1967, pp. 86-96.

3 Mrosovsky, N., Hibernation and the Hypothalamus, Appleton-Century-Crofts, New York, 1971, $287 \mathrm{pp}$.

4 SATINOFF, E., Impaired recovery from hypothermia after anterior hypothalamic lesions in hibernators, Science, 148 (1965) 399-400.

5 SATINOFF, E., Aberrations of regulation in ground squirrels following hypothalamic lesions, Amer. J. Physiol., 212 (1967) 1215-1220.

6 Satinoff, E., Disruption of hibernation caused by hypothalamic lesions, Science, 155 (1967) $1031-1033$.

7 Williams, B. A., and Heath, J. E., Responses to preoptic heating and cooling in a hibernator Citellus tridecemlineatus, Amer. J. Physiol., 218 (1970) 1654-1660 .

8 Wolf, G., AND Sutin, J., Fiber degeneration after lateral hypothalamic lesions in the rat, J. comp. Neurol., 127 (1966) 137-156. 